\title{
The Impact of Boreal Autumn SST Anomalies over the South Pacific on Boreal Winter Precipitation over East Asia
}

\author{
Juan $\mathrm{AO}^{1,2}$ and Jianqi SUN ${ }^{* 1,2}$ \\ ${ }^{1}$ Nansen-Zhu International Research Center, Institute of Atmospheric Physics, Chinese Academy of Sciences, Beijing 100029 \\ ${ }^{2}$ University of Chinese Academy of Sciences, Beijing 100049
}

(Received 12 March 2015; revised 21 September 2015; accepted 5 November 2015)

\begin{abstract}
The possible mechanism behind the variability in the dipole pattern of boreal winter precipitation over East Asia is analyzed in this study. The results show that the SST anomalies (SSTAs) over the South Pacific Ocean (SPO) in boreal autumn are closely related to the variability in the dipole pattern of boreal winter precipitation over East Asia. The physical link between the boreal autumn SPO SSTAs and the boreal winter East Asian precipitation dipole pattern is shown to mainly be the seasonal persistence of the SPO SSTAs themselves. The seasonal persistence of the SPO SSTAs can memorize and transport the signal of the boreal autumn SSTAs to the following winter, and then stimulates a meridional teleconnection pattern from the $\mathrm{SH}$ to the $\mathrm{NH}$, resulting in a meridional dipole pattern of atmospheric circulation over East Asia in boreal winter. As a major influencing factor, this dipole pattern of the atmospheric circulation can finally lead to the anomalous precipitation dipole pattern over East Asia in boreal winter. These observed physical processes are further confirmed in this study through numerical simulation. The evidence from this study, showing the impact of the SPO SSTAs in boreal autumn, not only deepens our understanding of the variability in East Asian boreal winter precipitation, but also provides a potentially useful predictor for precipitation in the region.
\end{abstract}

Key words: SST, boreal winter precipitation, dipolar pattern, atmospheric circulation, zonal wind

Citation: Ao, J., and J. Q. Sun, 2016: The impact of boreal autumn SST anomalies over the South Pacific on boreal winter precipitation over East Asia. Adv. Atmos. Sci., 33(5), 644-655, doi: 10.1007/s00376-015-5067-x.

\section{Introduction}

East Asia is a region with a high density of arable agriculture and a large human population. Anomalous precipitation in boreal winter, accompanied by intense snowfall and freezing events, can result in severe disasters in the region. Some studies have shown that, recently, boreal winter precipitation in East Asia has increased, and extreme precipitation is occurring more frequently (Sun et al., 2009a, 2010; Sun and Ao, 2013; Wang and He, 2013; Ao and Sun, 2015a, $2015 \mathrm{~b}$ ); and in terms of the future, the IPCC AR5 projection shows increasing winter precipitation in East Asia, with relatively larger magnitude over northern East Asia (Collins et al., 2013). These results indicate that the impact of boreal winter precipitation is enhancing, and will continue to do so. Thus, exploring the factors that influence boreal winter precipitation, and improving our ability to predict it, are both highly relevant research topics.

In previous research, a number of factors that impact upon the variability of boreal winter precipitation over East Asia have been revealed. For example, dominant atmospheric

\footnotetext{
* Corresponding author: Jianqi SUN

Email: sunjq@mail.iap.ac.cn
}

circulation modes, such as the East Asian jet stream (Yang et al., 2002), East Asian boreal winter monsoon (Zhou and Wu, 2010), and North Pacific oscillation (Wang et al., 2011), can produce anomalous boreal winter precipitation over East Asia. Snow cover is also considered a vital factor influencing boreal winter atmospheric circulation and precipitationrevealed by both observation analyses and numerical simulations (Cohen and Entekhabi, 1999, 2001; Cohen et al., 2002, 2007, 2014; Gong et al., 2002; Chen et al., 2003; Chen and Sun, 2003). A number of relatively recent studies have shown that the impact of sea ice on boreal winter precipitation has become significant in recent years (Liu et al., 2012; Ma et al., 2012, Li and Wang, 2013). In addition, variations in SST anomaly (SSTA) patterns, owing to their persistence and active role in air-sea interactions, have been highlighted as a key factor in diagnosing and predicting the variability in East Asian boreal winter precipitation (Bueh and Ji, 1999; Jin and Tao, 1999; Li and Bates, 2007; Feng et al., 2010; Zhou et al., 2010; Zhou et al., 2010; Wang and He, 2012; He et al., 2013; Zhang et al., 2014).

However, most previous studies focused on the impact of SSTA modes over the tropics and $\mathrm{NH}$; for example, ENSO, Atlantic multi-decadal oscillation, and western Pacific SSTAs. A recent study found that a tripole SSTA pattern 
existing in the South Pacific Ocean (SPO) during boreal winter could affect precipitation during the following spring over East China (Li et al., 2014). The result motivates us to ask whether SSTA patterns over the SPO, in particular during the preceding season, influence precipitation patterns over East Asia during boreal winter.

Therefore, this work focuses on the connection between boreal autumn SSTAs and boreal winter precipitation over East Asia, and the possible physical mechanisms involved in the connection. In addressing these issues, the intention is to deepen our understanding of boreal winter precipitation variability and improve its predictability.

\section{Data and methods}

Monthly precipitation data over East Asia on a $2.5^{\circ} \times 2.5^{\circ}$ grid were obtained from the Global Precipitation Climatology Project (GPCP) (Adler et al., 2003). Before the analysis, the data were transformed into boreal winter (DecemberFebruary; DJF) average precipitation. The monthly atmospheric circulation reanalysis datasets on a $2.5^{\circ} \times 2.5^{\circ}$ grid were provided by the NCEP-NCAR (Kalnay et al., 1996). The monthly Extended Reconstructed Sea Surface Temperature (ERSST v3b) dataset, on a $2^{\circ} \times 2^{\circ}$ grid, was acquired from the NOAA ESRL (Smith and Reynolds, 2003). The OLR data, also obtained from NOAA ESRL, are used to infer tropical convection. The OLR data are available from June 1974, with a missing period between March and December 1978.

According to the period of precipitation data and quality of the reanalysis data over the $\mathrm{SH}$, the analysis period was confined to 1979-2010 in this study. To investigate the influences of the preceding boreal autumn SSTAs, numerical simulations were performed with CAM5, which is the atmospheric component of CESM1_0_5. The "F_2000" component set was selected for CESM1_0_5, which used a pre- scribed climatology for SST and sea ice and an active land model (CLM), coupled with CAM5. The atmospheric composition was kept constant, at year 2000 values; that is, the $\mathrm{CO}_{2}$ concentration was at a constant $367.0 \mathrm{ppm}$ during the simulations. The simulations used a $1.9^{\circ}$ (lat) $\times 2.5^{\circ}$ (lon) finite volume grid, with 26 hybrid sigma pressure levels and a 30 minute integration time step (Gent et al., 2011).

\section{Results}

\subsection{EOF2 of boreal winter precipitation over East Asia}

The EOF calculated by the covariance matrix is firstly used to identify the spatial and temporal patterns of boreal winter precipitation over East Asia. Previous studies have analyzed the variability of the leading mode of winter precipitation over East Asia and the possible mechanisms (Ao and Sun, 2015a, 2015b). The leading mode of winter precipitation over East Asia exhibits highly consistent variability (figure not shown), and relatively larger values mainly over the southern and middle regions of East Asia. The leading EOF mode explains $19.9 \%$ of the total precipitation variance. In this research, the second mode (EOF2) of boreal winter precipitation will be analyzed.

The spatial pattern of boreal winter precipitation over East Asia, depicted by the EOF2 mode, exhibits a meridional dipolar pattern, and it explains $16.4 \%$ of the total variance in precipitation (Fig. 1a). The corresponding time series, of the EOF2 mode, indicates a strong linear trend and also interannual variability of boreal winter precipitation (figure not shown). The detrended and standardized time series of the EOF2 mode (dPC2) eliminates the impact of the linear trend, showing the interannual variability of the second EOF mode of boreal winter precipitation over East Asia (Fig. 1b). The $\mathrm{dPC} 2$ is used to analyze the relationships of boreal winter precipitation with atmospheric circulation and preceding boreal autumn SSTAs in the following sections.
EOF 2

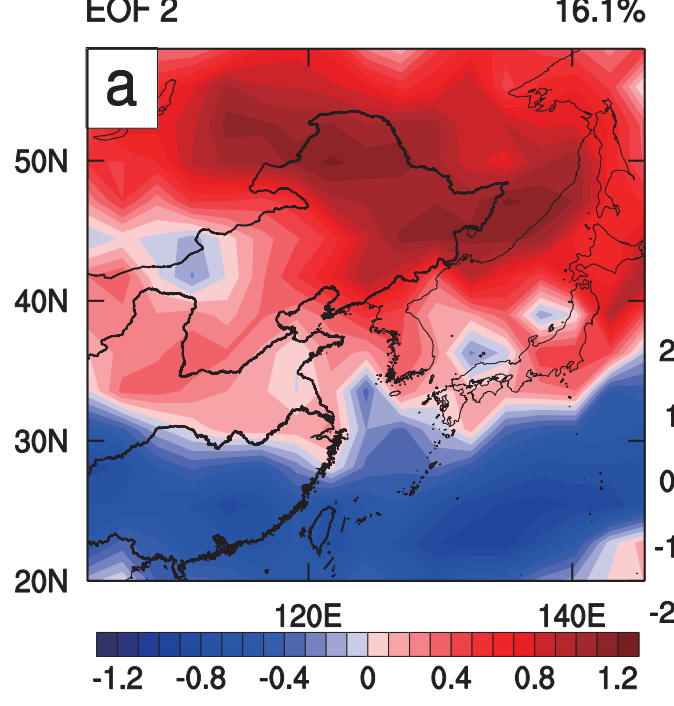

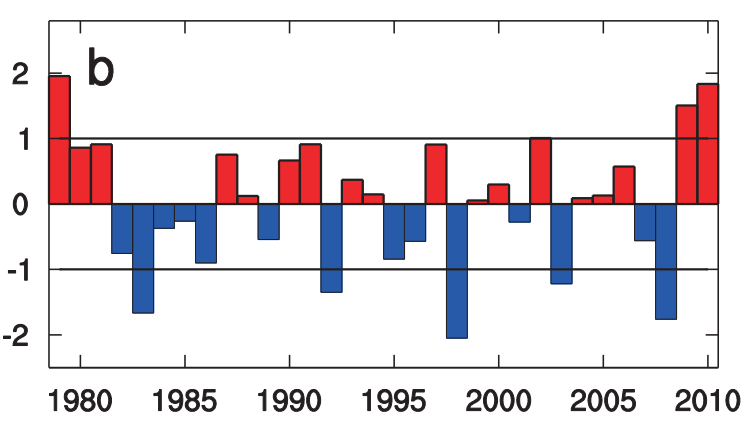

Fig. 1. The second EOF mode of standardized winter (DJF) precipitation over East Asia: (a) spatial distribution; (b) detrended and standardized time series (dPC2). 
3.2. Boreal winter atmospheric circulation anomalies and boreal autumn SSTAs associated with the EOF2 mode of boreal winter precipitation over East Asia

The regressed simultaneous geopotential height and wind at $500 \mathrm{hPa}$, vertical motion at $500 \mathrm{hPa}$, and vertically integrated water vapor flux, associated with the dPC2 of boreal winter precipitation reveals that there is a meridional dipole circulation pattern over East Asia (Fig. 2). An anomalous cyclonic circulation is centered over the Lake Baikal region (Fig. 2a), which leads to anomalous ascending motion over northern East Asia (Fig. 2b) and also enhances the water vapor transportation to northern East Asia by westerly flow and from the Pacific (Fig. 2c), ultimately favoring more precipitation over northern East Asia. In contrast, an anomalous anticyclone covers southern China, extending to the Middle East, which results in anomalous descending motion over southern
East Asia and also weakens the transportation of warm and moist air from the low latitudes, consequently leading to less precipitation over southern East Asia. This dipolar pattern is the most important circulation factor responsible for the variability of the dipole pattern of boreal winter precipitation over East Asia.

In order to investigate the relationship between the East Asian boreal winter precipitation dipole pattern and the SPO SST variability, the regressed preceding autumn SSTAs associated with the dPC2 of boreal winter precipitation over East Asia is calculated. The significant SSTAs show a tripole pattern over the SPO, with a remarkable negative SSTA present mainly over the southern SPO and significant positive SSTAs over the northeastern and northwestern SPO (Fig. 3). Moreover, this boreal autumn SSTA pattern still exists in the following boreal wintertime (figure not shown, similar to Fig. 3). These results show that the tripole pattern of SSTAs over
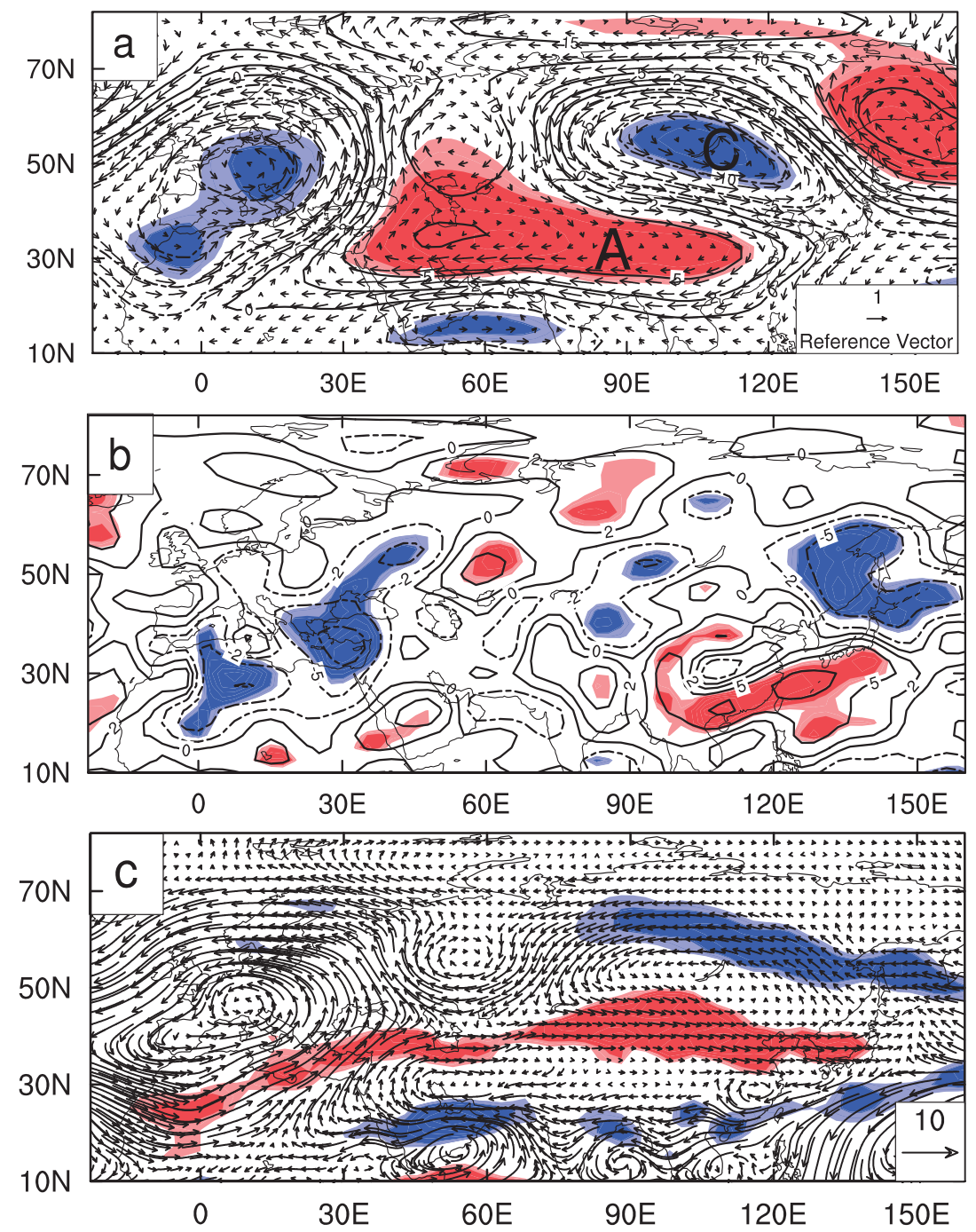

Fig. 2. Linear regressions of boreal winter (a) geopotential height (gpm) and wind $\left(\mathrm{m} \mathrm{s}^{-1}\right)$ at $500 \mathrm{hPa}$, (b) vertical motion $\left(10^{-3} \mathrm{~Pa} \mathrm{~s}^{-1}\right)$ at $500 \mathrm{hPa}$, and (c) vertically integrated water vapor flux $\left(\mathrm{kg} \mathrm{m}^{-1} \mathrm{~s}^{-1}\right)$, against $\mathrm{dPC} 2$. The dark (light) shaded areas are significant at the $95 \%(90 \%)$ confidence level. 


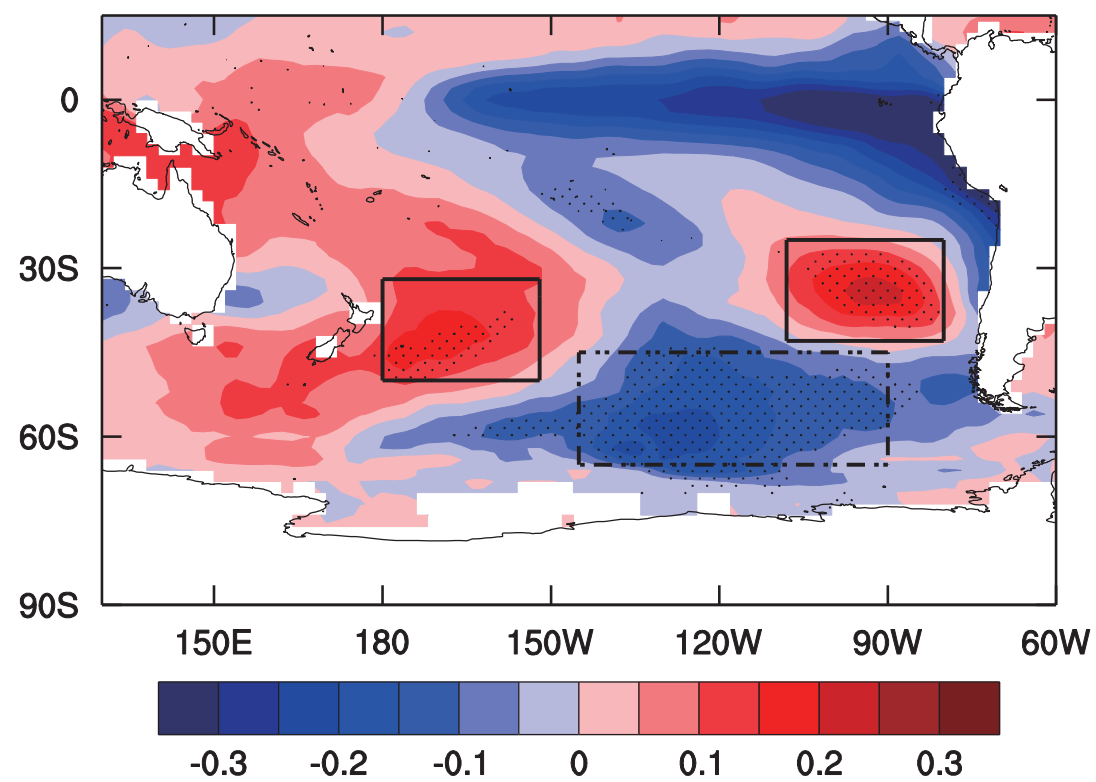

Fig. 3. Linear regressions of boreal autumn SSTAs $\left({ }^{\circ} \mathrm{C}\right)$ against dPC2. Dotted areas are significant at the $95 \%$ confidence level.

the SPO has a relationship with the second mode of boreal winter precipitation over East Asia.

To further quantify the relationship of the tripole pattern of SSTAs over the SPO and the second mode of boreal winter precipitation over East Asia, an SSTA index (SSTI) is defined as the difference between the standardized averaged SSTs over the positive SSTA regions (P; the black solid rectangle in Fig. 3) and the negative SSTA region (N; the black dashed rectangle in Fig. 3), based on the formula: SSTI $=$ $\left(1 / 4 \mathrm{P}_{\text {west }}+1 / 4 \mathrm{P}_{\text {east }}\right)-1 / 2 \mathrm{~N}\left(\mathrm{P}_{\text {west }} / \mathrm{P}_{\text {east }}\right.$; the west/east solid rectangle in Fig. 3). The correlation coefficient of the detrended boreal autumn SSTI and the dPC2 of boreal winter precipitation is 0.72 , significant at the $99 \%$ confidence level; this means that the tripolar pattern of boreal autumn SSTAs over the SPO does have a good relationship with the variation of the dipolar mode of boreal winter precipitation over East Asia.

\subsection{How do the boreal autumn SSTAs over the SPO affect the boreal winter atmospheric circulation and precip- itation over East Asia?}

\subsubsection{Observational analysis}

The previous section showed that the boreal autumn tripole pattern of SSTAs over the SPO is connected to the second mode of boreal winter precipitation over East Asia. Here, the possible mechanism responsible for this connection is explored. Given that the SSTAs generally have good persistence, we deduce that the seasonal persistence of the SSTAs could be a possible mechanism to memorize and transport the signal of the boreal autumn SSTAs into the following boreal winter, and then impact upon the atmospheric circulation and precipitation. Therefore, the SSTI in boreal winter is also computed, and the correlation coefficient of the SSTIs in boreal autumn and winter is 0.72 , significant at the $99 \%$ confidence level. After removing the SSTI trend (Fig. 4), the two SSTIs also co-very well, with a correlation coefficient of 0.70. These results indicate that the SSTA signal over the SPO does have good persistence from boreal autumn through to boreal winter.

To further understand how the SPO SSTAs persist from the boreal autumn to winter, the evolution of the anomalous SSTs and surface winds over the SPO from the boreal autumn to winter are analyzed (Fig. 5). The anomalous SSTs and surface winds are calculated by compositing the corresponding SST and surface winds in the abnormal years of the boreal winter precipitation dipole pattern; the abnormal years are defined as occurring when the detrended and normalized time series of the boreal winter precipitation's second EOF mode are greater than 1 , or less than -1 . It is found that the SPO SSTAs in boreal autumn correspond to an anomalous anticyclone in the midlatitudes, and a cyclone in the high latitudes, of the SPO. On the one hand, northerly anomalies of the anticyclone can bring warmer water from the low latitudes to the midlatitudes, leading to the SST warming over the northern SPO; while on the other hand, the midlatitude anticyclone corresponds to sunny weather, which favors more solar radiation being received by the sea surface, and also contributes to the SST warming over the northern SPO. However, the southwesterly anomalies between the anticyclone and cyclone will bring colder water from the high latitudes to the midlatitudes, leading to SST cooling over the southern SPO. Additionally, the distribution of anomalous warm SST over the northern SPO and cold SST over the southern SPO can enlarge the meridional temperature gradient over the SPO region. According to thermal wind theory, the enhanced meridional temperature gradient can enhance the zonal wind between the warm and cold SSTAs over the SPO. The enhanced west- 


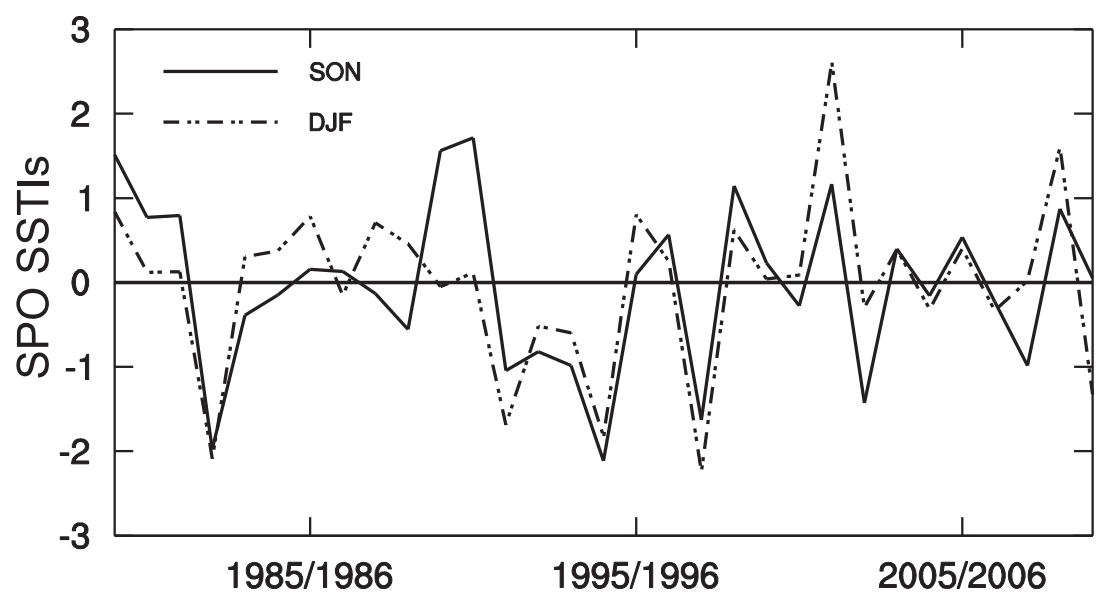

Fig. 4. Detrended and standardized SPO SSTIs in boreal autumn (1979-2009) and winter (1980-2010). The former year of x-axis corresponds to autumn (SON), and the latter year corresponds to winter (DJF).
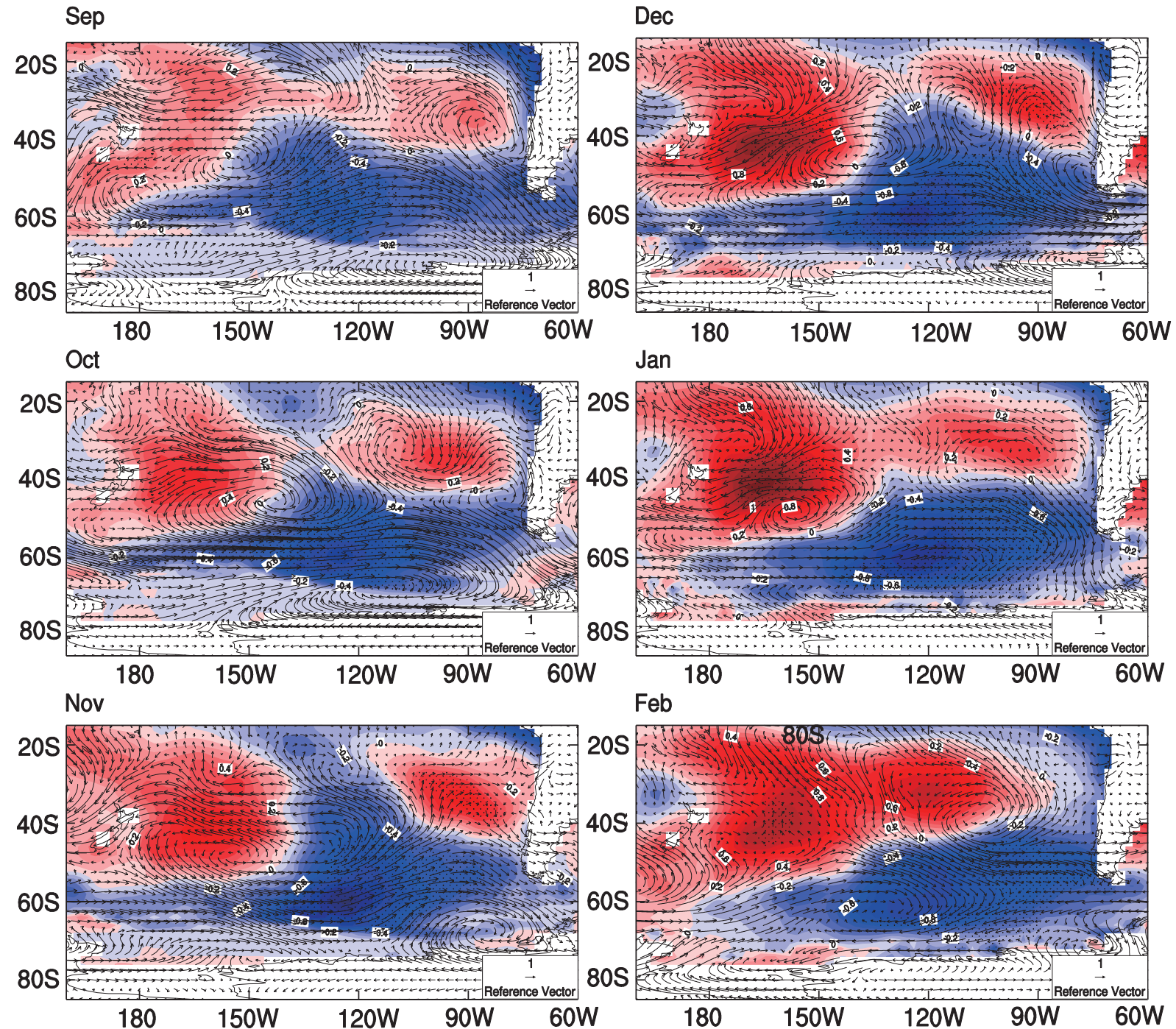

Fig. 5. Evolution of anomalous SSTs $\left({ }^{\circ} \mathrm{C}\right)$ and surface winds $\left(\mathrm{m} \mathrm{s}^{-1}\right)$ over the SPO from September to the following February. Dotted areas are significant at the 95\% confidence level. 
erly can then enhance the anomalous cyclone over the southern SPO and anticyclone over the northern SPO. Thus, there is a positive feedback mechanism between ocean and atmosphere, which leads to the persistence of the autumn SPO SSTAs to winter.

Further, the atmospheric circulation patterns associated with the SSTAs over the SPO are investigated. A regression of the boreal winter zonal winds associated with the detrended boreal winter SSTI indicates that the SPO SSTA pattern is related to two meridional teleconnection patterns of zonal wind (Fig. 6a). One is over the eastern Pacific, and the other is over the Eastern Hemisphere. The teleconnection pattern of the zonal wind from the $\mathrm{SH}$ to the $\mathrm{NH}$ over the Eastern Hemisphere leads to a dipole pattern of geopotential height over East Asia (Fig. 6b); this pattern is quite similar to the atmospheric pattern associated with the dPC2 of boreal winter precipitation over East Asia (Fig. 2a).

The atmospheric circulation associated with the detrended SSTI in boreal autumn (Fig. 7) shows a quite similar but weaker atmospheric circulation pattern to the regres- sion of the boreal winter zonal winds associated with the detrended boreal winter SSTI (Fig. 6). Because the variability of the SPO SSTAs in boreal autumn and winter is highly consistent, the two SSTIs are related to a similar atmospheric circulation pattern in boreal winter.

From an observational analysis viewpoint, the above results provide good evidence of the persistence of SPO SSTAs as the connection between the boreal autumn SPO SSTA pattern and the East Asian winter precipitation.

\subsubsection{Numerical simulation}

The observational data indicate that interhemispheric meridional teleconnection patterns could be responsible for the connection between the SPO SSTAs and the East Asian winter circulation and precipitation. In this section, a numerical simulation is used to investigate whether or not these interhemispheric meridional teleconnection patterns are induced by the SPO SSTAs.

To simulate SSTs as realistically as possible, we impose observed boreal autumn SSTAs (Fig. 8a) from August to

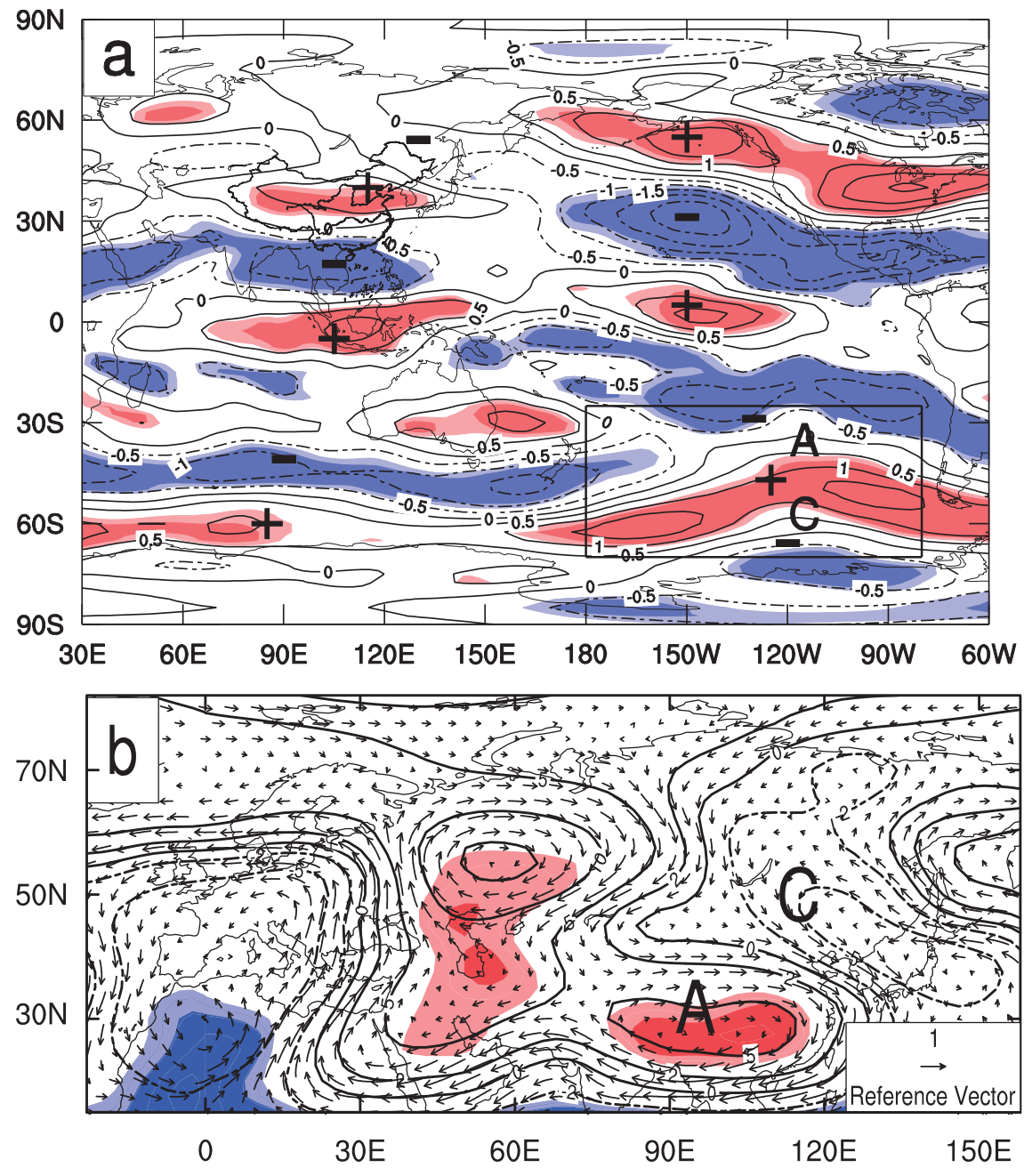

Fig. 6. Linear regressions of boreal winter (a) zonal wind $\left(\mathrm{m} \mathrm{s}^{-1}\right)$ and (b) geopotential height (gpm) and wind $\left(\mathrm{m} \mathrm{s}^{-1}\right)$ at $500 \mathrm{hPa}$, against the detrended and standardized boreal winter SSTI over the SPO. The dark (light) shaded areas are significant at the 95\% (90\%) confidence level. 

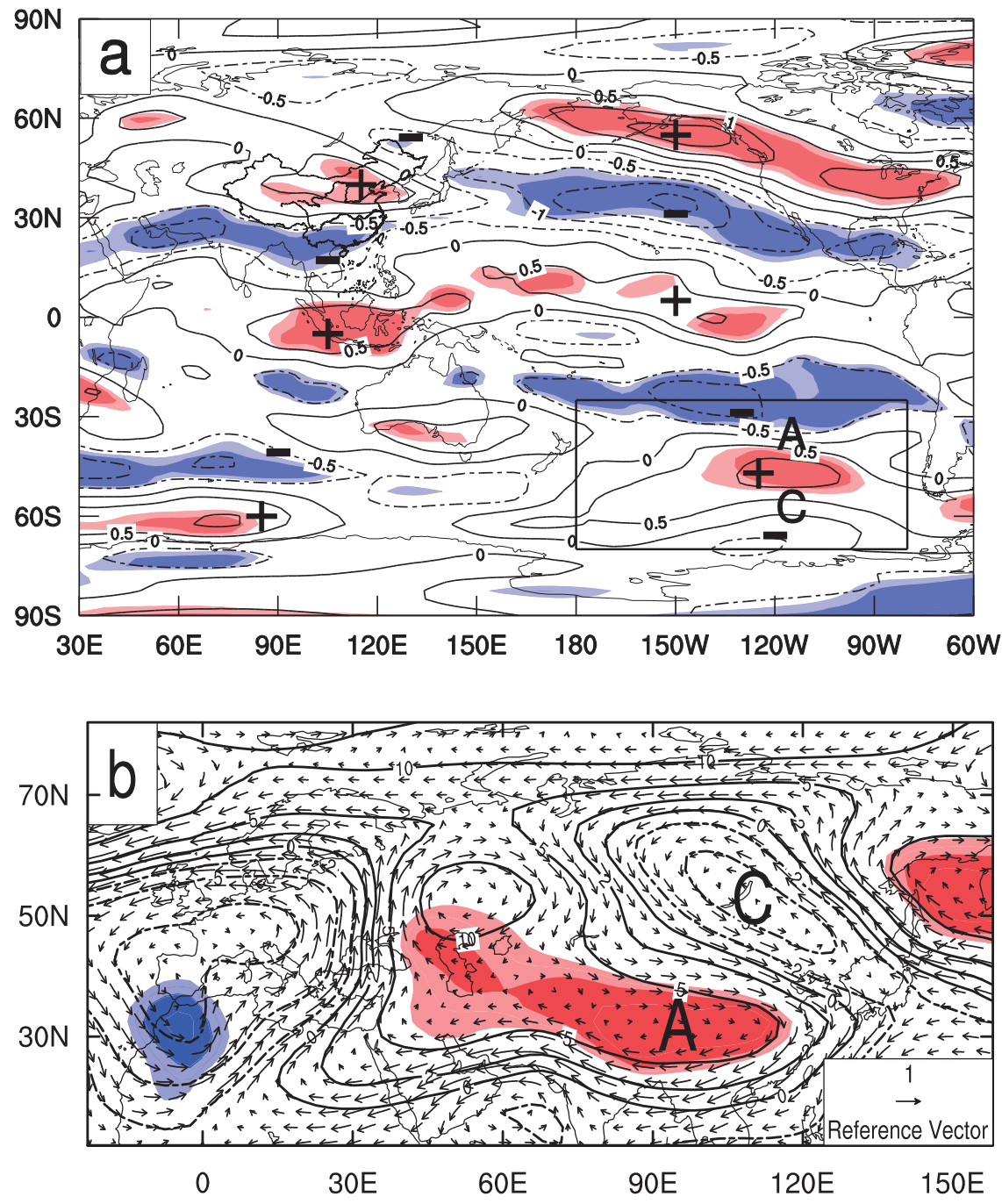

Fig. 7. As in Fig. 6 but for boreal autumn SSTI.
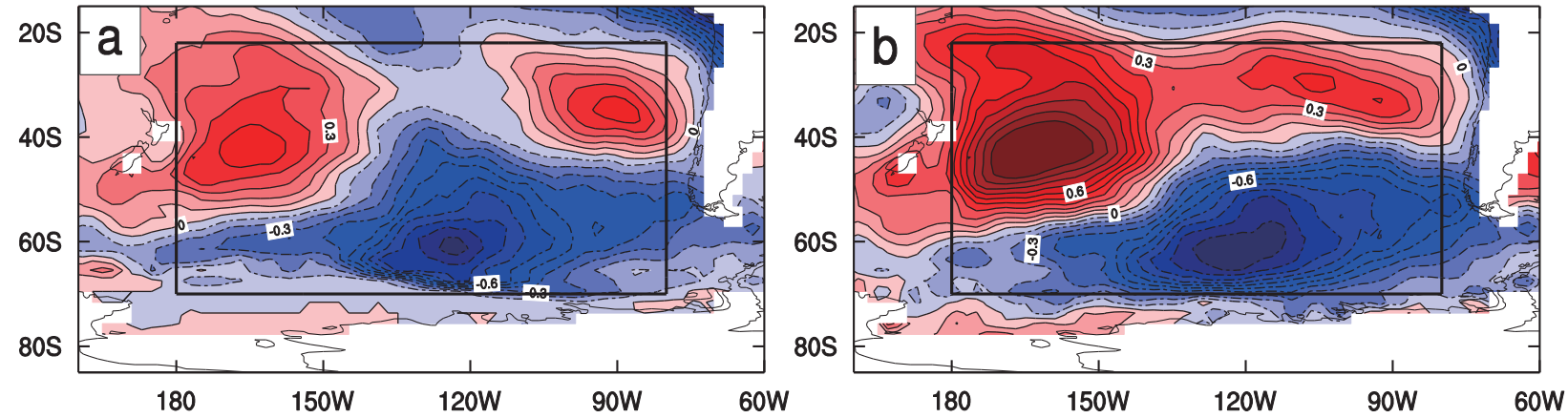

Fig. 8. SSTAs $\left({ }^{\circ} \mathrm{C}\right)$ over the SPO in boreal (a) autumn and (b) winter, imposed in the numerical simulation.

November (August as the spin-up time), and boreal winter SSTAs (Fig. 8b) from December to February, over the SPO in the numerical simulations. The boreal autumn and boreal winter SSTAs are calculated separately by compositing the corresponding SSTAs in the abnormal years of the boreal winter precipitation dipole pattern; the abnormal years are defined as occurring when the detrended and normalized time series of the boreal winter precipitation's second EOF mode are greater than 1 , or less than -1 . To eliminate the strong SST gradients over the four borders of the SSTA regions, the SSTAs are linearly decreased to $0^{\circ} \mathrm{C}$ across five points. A 30-year run with the model's climatological SST and sea-ice boundary conditions is performed; the average for the last 20 years is defined as the control run (EXP0). The sensitivity 
experiment (EXP1) is similar to EXP0, but with the SSTAs imposed over the SPO region in boreal autumn and boreal winter; the average for the last 20 years of EXP1 is compared with EXP0.

Anomalies of $500 \mathrm{hPa}$ zonal wind (Fig. 9a), geopotential height and winds over Eurasia (Fig. 9b), and total precipi-
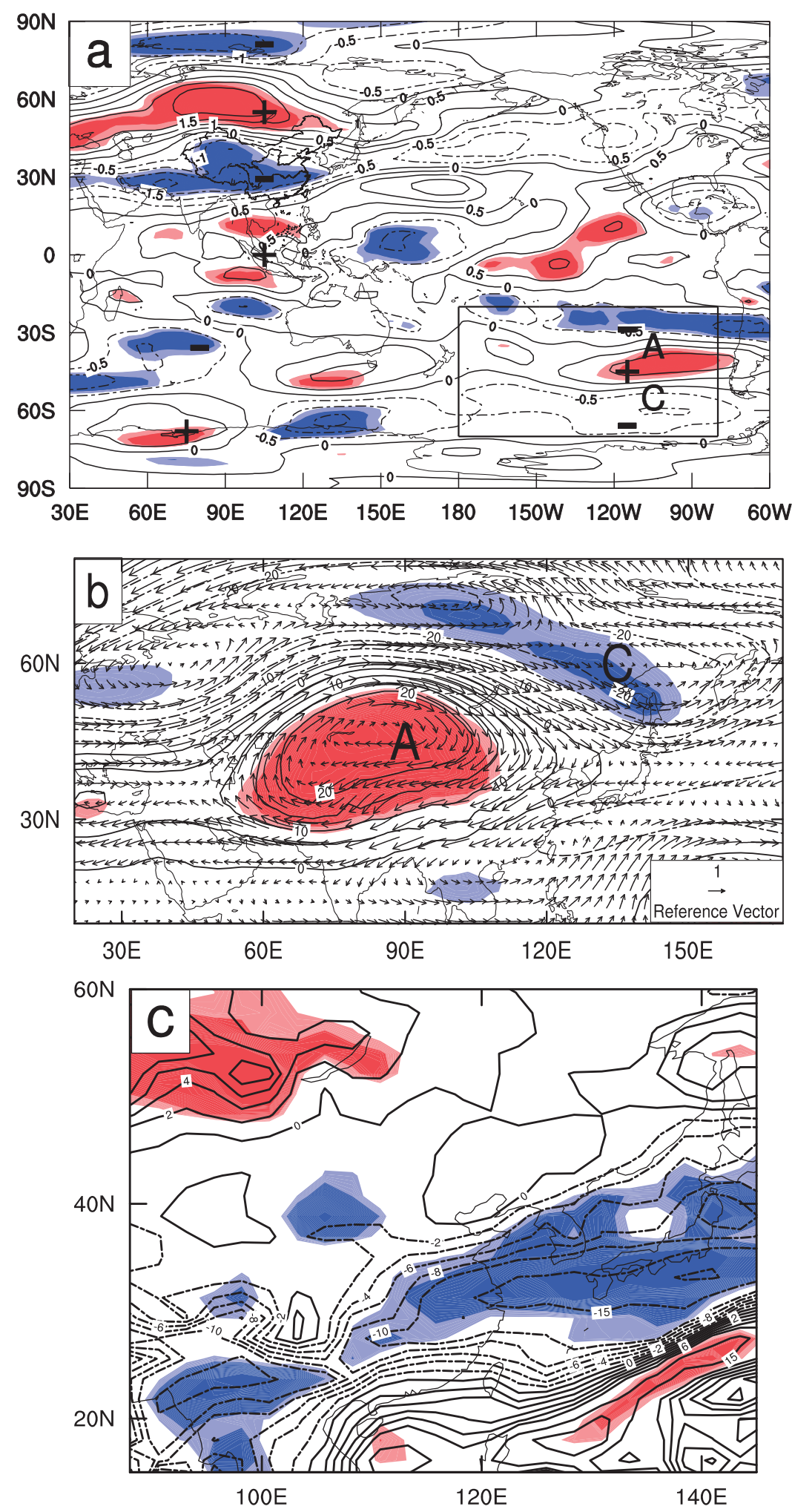

Fig. 9. Differences of boreal winter (a) zonal wind at $500 \mathrm{hPa}\left(\mathrm{m} \mathrm{s}^{-1}\right)$, (b) geopotential height $(\mathrm{gpm})$ and wind $\left(\mathrm{m} \mathrm{s}^{-1}\right)$ at $500 \mathrm{hPa}$, and (c) precipitation $\left(\mathrm{mm} \mathrm{month}{ }^{-1}\right.$ ) over East Asia, between EXP1 and EXP0. The dark (light) shaded areas are significant at the $95 \%$ (90\%) confidence level. 


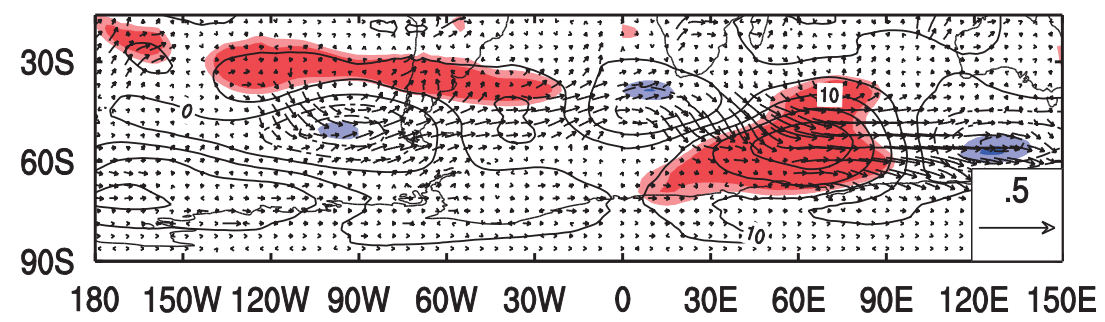

Fig. 10. Differences of the boreal winter geopotential height (gpm) at $500 \mathrm{hPa}$ between EXP1 and EXP0 and the related wave activity flux $\left(\mathrm{m}^{2} \mathrm{~s}^{-2}\right)$. The dark (light) shaded areas are significant at the $95 \%(90 \%)$ level.

tation over East Asia (Fig. 9c) in the simulation forced by the SPO SSTA pattern are similar to the observation. These results provide a possible mechanism for the SPO SSTAs affecting atmospheric circulations and winter precipitation over East Asia. The distribution of anomalous warm SST over the northern SPO and cold SST over the southern SPO can enlarge the meridional temperature gradient over the SPO region. According to thermal wind theory, the enhanced meridional temperature gradient can enhance the zonal wind between the warm and cold SSTA over the SPO. The enhanced westerly can then lead to an anomalous cyclone over the southern SPO and anticyclone over the northern SPO. Such changes of the atmospheric circulation enhance the eastward Rossby wave propagation reflected by the Rossby wave activity flux (Fig. 10), which further causes anomalous atmospheric circulations over the Eastern Hemisphere. The study of Ambrizzi et al. (1995) indicated that the southern Indian Ocean is an arc-like route of equatorward Rossby wave propagation. Thus, along this route, the SPO SSTA-related wave train propagates equatorward over the southern Indian Ocean, resulting in anomalous tropical climate. Accordingly, in the anomalous SPO SST years, the tropical convection has changed (Fig. 11). The simulated OLR features are similar to the observation, although the observed signal is stronger than the simulated. As shown in Fig. 12, in response to the SPO SSTA, the convection is enhanced over the western tropical Pacific Ocean and depressed over the western tropical Indian Ocean. Such a dipole convective pattern indicates changes in the Walker-like zonal circulation over the tropical Indian Ocean. An OLR index is defined as the difference between the regional means of OLR over the two rectangular regions in Fig. 12. Table 1 shows the quantitative relationship between the SPO SSTI and the OLR index. The table suggests that there is a close relationship between the SPO SSTA and tropical convection. Figure 12 also implies a strong ENSO signal in the tropical convection. To further investigate the relationship between the SPO SSTA and tropical convection, the ENSO signal is removed from the OLR index based on the linear regression method using the Niño3.4 index, and the new correlation coefficient is also listed in Table 1. The result still shows a close relationship between the SPO SSTA and tropical convection.

According to traditional wave theories, Rossby waves cannot move across the equator to the other hemisphere
Table 1. Correlation coefficients of the detrended and standardized OLR index with the SPO SSTI and APC2 in boreal winter are shown in first row. Correlation coefficients after removing the ENSO signal are shown in second row.

\begin{tabular}{ccc}
\hline & SPO SSTI & dPC2 \\
\hline OLR index & 0.70 & 0.54 \\
OLR index-Niño3.4 & 0.47 & 0.56 \\
\hline
\end{tabular}

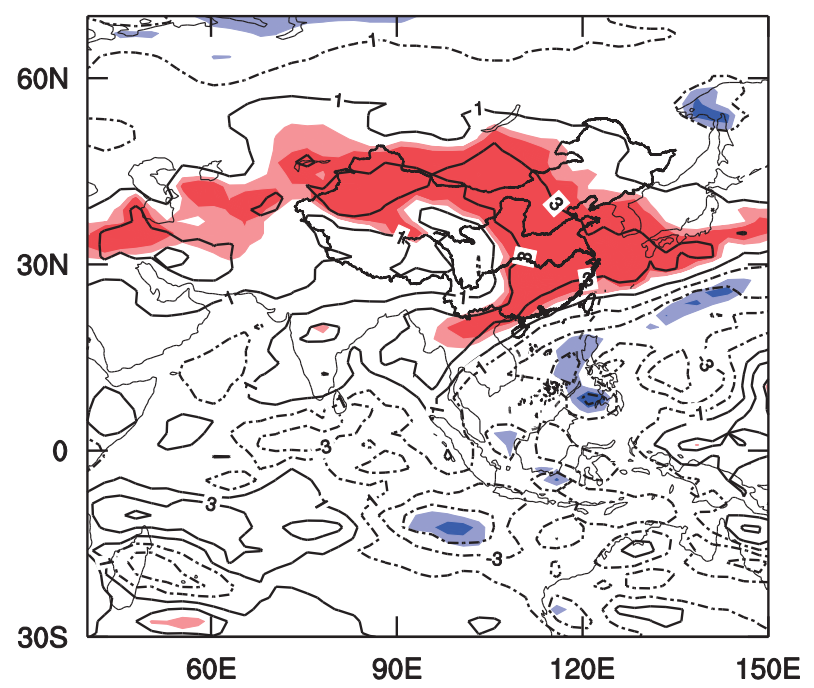

Fig. 11. Differences of OLR $\left(\mathrm{W} \mathrm{m}^{-2}\right)$ between EXP1 and EXP0 in boreal winter. The dark (light) shaded areas are significant at the $95 \%$ (90\%) confidence level.

due to prevailing easterlies (e.g., Ambrizzi et al., 1995); meanwhile, the tropical climate associated with the Rossby wave can connect the climate over the other hemisphere (e.g., Matthews and Kiladis, 2000; Sun et al., 2009b). Thus in this study, the SPO SSTA-related tropical convection can transport the SPO SSTA influence to East Asia. The regression of geopotential height at $500 \mathrm{hPa}$ against the OLR index after removing the ENSO signal is shown in Fig. 13. Over the SH, the anomalous circulation shows a wave train pattern, propagating equatorward over the southern Indian Ocean, similar to the SPO SSTA-related circulation over the region (Figs. $6 a$ and 9a). Over East Asia, the atmospheric circulation pat- 


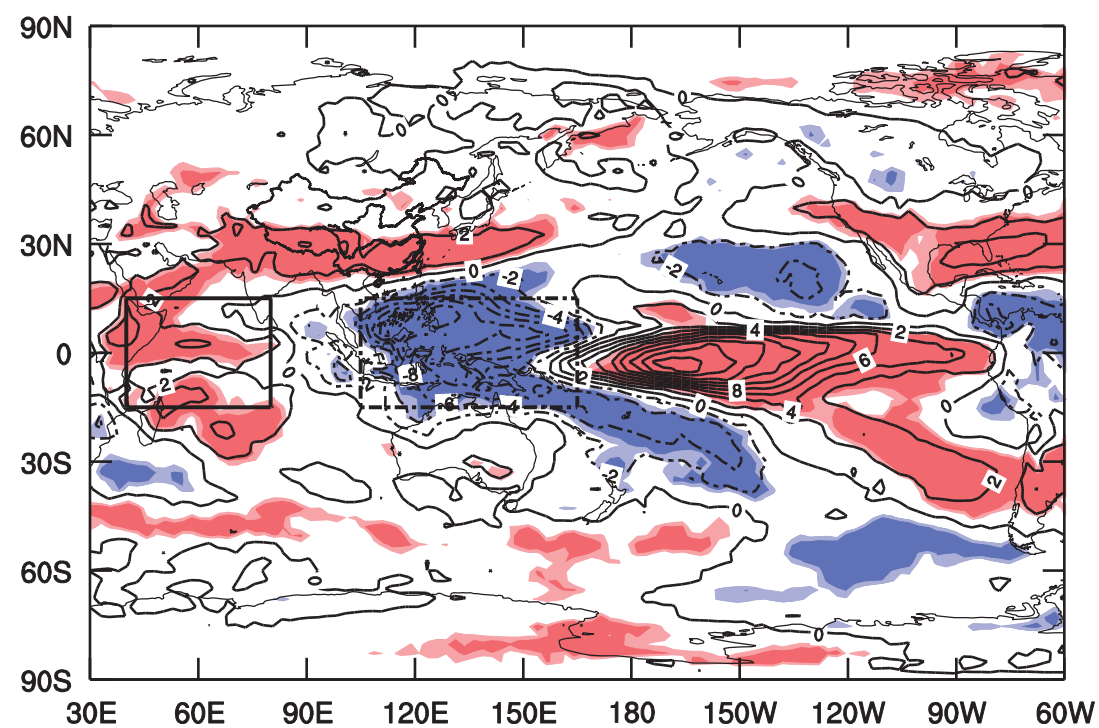

Fig. 12. Linear regressions of OLR $\left(\mathrm{W} \mathrm{m}^{-2}\right)$ against the detrended and standardized SSTI over SPO in boreal winter. The dark (light) shaded areas are significant at the 95\% (90\%) confidence level. The rectangles indicate the two key OLR regions.

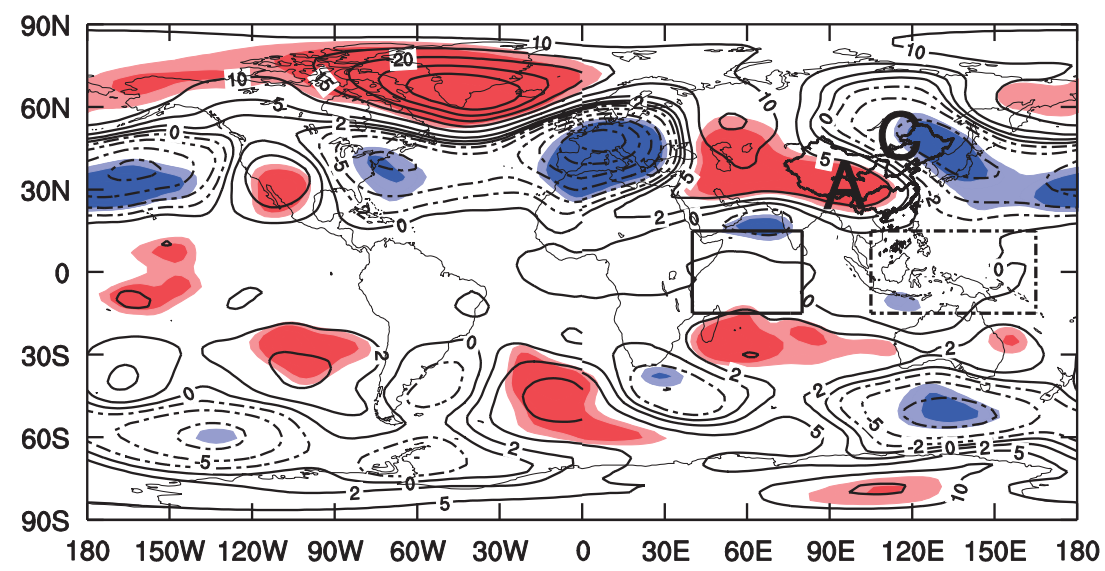

Fig. 13. Linear regressions of $500 \mathrm{hPa}$ geopotential height (gpm) against the detrended and standardized OLR index after removing ENSO signal in boreal winter. The dark (light) shaded areas are significant at the 95\% (90\%) confidence level. The rectangles indicate the two key OLR regions.

tern is similar to the regressed pattern against dPC2 (Fig. 2a), with anomalous cyclonic circulation centered over the northern part of East Asia and an anticyclone covering southern China and extending to the Middle East, showing a meridional dipole circulation pattern over East Asia. Some previous studies have shown that the tropical convection can stimulate a wave train pattern over East Asia (Nitta, 1987; Huang and Sun, 1994). Thus, the tropical convection can excite the atmospheric circulation over East Asia, which further results in anomalous winter precipitation over the region. Table 1 also confirms the relationship between the tropical convection and East Asian winter precipitation, showing significant correlations between the two indices.

There are similarities over the Eastern Hemisphere between observations and simulations (see Figs. 6a and 9a); but in contrast, there are large differences over the Western Hemisphere. There is an interhemispheric teleconnection pattern over the Western Hemisphere according to observations (Fig. 6a); however, in the simulation (Fig. 9a), the meridional teleconnection is confined to the tropical and southern areas of the East Pacific. This difference could be related to the absence of the ENSO signal in the simulation. In the observation, there is a high correlation between the SPO SSTIs and the ENSO index, and the ENSO-related circulation pattern shows a similar interhemispheric teleconnection over the East Pacific. However, in the numerical simulation, the atmospheric circulation pattern is only related to the SPO SSTAs. Thus, compared to the observational analysis, the existence of the interhemispheric teleconnection pattern over the Eastern Hemisphere and absence of the interhemispheric telecon- 
nection pattern over the Western Hemisphere (i.e., the East Pacific) in the numerical simulation, indicates that the interhemispheric teleconnection pattern over the Eastern Hemisphere is a physical way to transport the influence of the SPO SSTAs to East Asia.

Our study indicates that the signal of boreal autumn SSTAs over the SPO can be kept to the following winter owing to the persistence of the SSTA, and then the boreal winter SSTAs over the SPO can stimulate the interhemispheric teleconnection pattern to affect winter precipitation over East Asia. On the other hand, the SPO SSTAs exist in the boreal autumn. The sole impact of the SPO SSTA should therefore also be investigated, to improve our understanding of the influencing mechanism. Thus, we also ran the experiments using only the SSTAs in boreal autumn. The results showed that the anomalies of atmospheric circulation and precipitation still appear in the numerical simulation (figure not shown); however, the signals are much weaker compared with the simulation including both autumn and winter SSTAs. These results indicate that the circulation anomalies induced solely by the SPO SSTAs in boreal autumn contribute weakly to the winter precipitation over East Asia. The persistence of the SSTA signal from boreal autumn to winter could play a more important role in the connection between the boreal autumn SPO SSTA and winter East Asian precipitation.

The numerical simulation further confirms that the SPO SSTA mode is an influencing factor for boreal winter precipitation over East Asia; within this process, the seasonal persistence of the SPO SSTAs and the interhemispheric teleconnection pattern play an important role.

\section{Summary and conclusions}

This paper investigates the spatial and temporal features of the second EOF mode of boreal winter precipitation over East Asia during the period 1979-2010, and further explores the possible influencing factors. The second EOF mode shows a meridional dipole pattern, which explains $16.4 \%$ of the total variance and exhibits a strong interannual variability. Circulation analysis indicates that the atmospheric circulation associated with the EOF2 mode of boreal winter precipitation over East Asia is a dipole pattern: there is one center over the Lake Baikal region and another over southern China. This meridional dipole pattern is the dominant pattern impacting upon the dipole pattern of precipitation over East Asia.

After diagnosing the relationship between the East Asian winter precipitation EOF2 mode and SST variability, the influence of the SPO SSTAs in boreal autumn on the boreal winter precipitation dipole mode over East Asia was revealed. The possible main mechanism, through which the SPO SSTAs in the boreal autumn affect the East Asian boreal winter precipitation, is considered to be the SSTA's seasonal persistence. The persistence of the SPO SSTAs means that the signal is memorized and transported from boreal autumn through to winter, and then stimulates the interhemispheric teleconnection pattern over the East Hemisphere. This merid- ional teleconnection pattern plays an important role in the influence of the SPO SSTAs on the atmospheric circulation over East Asia, resulting in a dipole pattern. This dipole pattern is the dominant factor influencing the variability of the dipole pattern of boreal winter precipitation over East Asia. These results were further confirmed through a numerical simulation. Therefore, the SPO SSTA pattern revealed in this study is valuable in terms of our understanding of the variability in East Asian winter precipitation and improving predictions in the future.

Acknowledgements. This work was jointly supported by the Special Fund for Public Welfare Industry (meteorology) (Grant No. GYHY201306026) and the National Natural Science Foundation of China (Grant Nos. 41421004 and 41522503).

\section{REFERENCES}

Adler, R. F., and Coauthors, 2003: The Version-2 global precipitation climatology project (GPCP) monthly precipitation analysis (1979-Present). Journal of Hydrometeorology, 4, 11471167.

Ambrizzi, T., B. J. Hoskins, and H. H. Hsu, 1995: Rossby wave propagation and teleconnection patterns in the austral winter. J. Atmos. Sci., 52, 3661-3672.

Ao, J., and J. Q. Sun, 2015a: Decadal change in factors affecting winter precipitation over eastern China. Climate Dyn., doi: 10.1007/s00382-015-2572-7.

Ao, J., and J. Q. Sun, 2015b: Connection between November snow cover over Eastern Europe and winter precipitation over East Asia. Int. J. Climatol., doi: 10.1002/joc.4484.

Bueh, C., and L. R. Ji, 1999: Anomalous activity of East Asian winter monsoon and the tropical Pacific SSTA. Chinese Science Bulletin, 44, 890-898.

Cohen, J., and D. Entekhabi, 1999: Eurasian snow cover variability and northern hemisphere climate predictability. Geophys. Res. Lett., 26, 345-348.

Cohen, J., and D. Entekhabi, 2001: The influence of snow cover on northern hemisphere climate variability. Atmos.-Ocean, 39, $35-53$.

Cohen, J., D. Salstein, and K. Saito, 2002: A dynamical framework to understand and predict the major Northern Hemisphere mode. Geophys. Res. Lett., 29(10), 51-54.

Chen, H. S., and Z. B. Sun, 2003: The effects of Eurasian snow cover anomaly on winter atmospheric general circulation Part I. observational studies. Chinese J. Atmos. Sci., 27, 304-316. (in Chinese)

Chen, H. S., Z. B. Sun, and W. J. Zhu, 2003: The effects of Eurasian snow cover anomaly on winter atmospheric general circulation Part II. Model simulation. Chinese J. Atmos. Sci., 27, 847-860. (in Chinese)

Cohen, J., M. Barlow, P. J. Kushner, and K. Saito, 2007: Stratosphere-troposphere coupling and links with Eurasian land surface variability. J. Climate, 20, 5335-5343.

Cohen, J., J. C. Furtado, J. Jones, M. Barlow, D. Whittleston, and D. Entekhabi, 2014: Linking Siberian snow cover to precursors of stratospheric variability. J. Climate, 27, 5422-5432.

Collins, M., and Coauthors, 2013: Long-term climate change: projections, commitments and irreversibility. Climate Change 2013: The Physical Science Basis. Contribution of Working 
Group I to the Fifth Assessment Report of the Intergovernmental Panel on Climate Change, T. F. Stocker et al., Eds., Cambridge University Press, 1029-1136.

Feng, J., L. Wang, W. Chen, S. K. Fong, and K. C. Leong, 2010: Different impacts of two types of Pacific Ocean warming on Southeast Asian rainfall during boreal winter. J. Geophys. Res., 115, D24122.

Gent, P. R., and Coauthors, 2011: The community climate system model Version 4. J. Climate, 24, 4973-4991.

Gong, G., D. Entekhabi, and J. Cohen, 2002: A large-ensemble model study of the wintertime AO-NAO and the role of interannual snow perturbations. J. Climate, 15, 3488-3499.

He, S. P., H. J. Wang, and J. P. Liu, 2013: Changes in the relationship between ENSO and Asia-Pacific midlatitude winter atmospheric circulation. J. Climate, 26, 3377-3393.

Huang, R. H., and F. Y. Sun, 1994: Impacts of the thermal state and the convective activities in the tropical western warm pool on the summer climate anomalies in East Asia. Chinese J. Atmos. Sci., 18, 141-151. (in Chinese)

Jin, Z. H., and S. Y. Tao, 1999: A study on the relationships between ENSO cycle and rainfalls during summer and winter in Eastern China. Chinese J. Atmos. Sci., 23, 663-672. (in Chinese)

Kalnay, E., and Coauthors, 1996: The NCEP/NCAR 40-year reanalysis project. Bull. Amer. Meteor. Soc., 77, 437-470.

Li, S. L., and G. T. Bates, 2007: Influence of the Atlantic multidecadal oscillation on the winter climate of East China. Adv. Atmos. Sci., 24, 126-135, doi: 10.1007/s00376-007-0126-6.

Li, F., and H. J. Wang, 2013: Autumn Sea Ice cover, winter northern hemisphere annular mode, and winter precipitation in Eurasia. J. Climate, 26, 3968-3981.

Li, G., C. Y. Li, Y. K. Tan, and X. Wang, 2014: Observed relationship of boreal winter South Pacific Tripole SSTA with Eastern China rainfall during the following boreal spring. J. Climate, 27, 8094-8106.

Liu, J. P., J. A. Curry, H. J. Wang, M. R. Song, and R. M. Horton, 2012: Impact of declining Arctic sea ice on winter snowfall. Proc. Natl. Acad. Sci., 109, 4074-4079.

Ma, J. H., H. J. Wang, and Y. Zhang, 2012: Will boreal winter precipitation over China increase in the future? An AGCM simulation under summer "ice-free Arctic" conditions. Chinese Science Bulletin, 57, 921-926.

Matthews, A. J., and G. N. Kiladis, 2000: A model of Rossby waves linked to submonthly convection over the eastern Trop- ical Pacific. J. Atmos. Sci., 57, 3785-3798.

Nitta, T., 1987: Convective activities in the tropical western Pacific and their impact on the Northern Hemisphere summer circulation. J. Meteor. Soc. Japan, 65, 373-390.

Smith, T. M., and R. W. Reynolds, 2003: Extended reconstruction of global Sea surface temperatures based on COADS data (1854-1997). J. Climate, 16, 1495-1510.

Sun, J. Q., and J. Ao, 2013: Changes in precipitation and extreme precipitation in a warming environment in China. Chinese Science Bulletin, 58, 1395-1401.

Sun, J. Q., H. J. Wang, and W. Yuan, 2009a: A preliminary investigation on causes of the catastrophic snowstorm in March, 2007 in the northeastern parts of China. Acta Meteorologica Sinica, 67, 469-477. (in Chinese)

Sun, J. Q., H. J. Wang, and W. Yuan, 2009b: A possible mechanism for the co-variability of the boreal spring Antarctic Oscillation and the Yangtze River valley summer rainfall. Int. J. Climatol., 29, 1276-1284, doi: 10.1002/joc.1773.

Sun, J. Q., H. J. Wang, W. Yuan, and H. P. Chen, 2010: Spatialtemporal features of intense snowfall events in China and their possible change. J. Geophys. Res., 115, D16110.

Wang, H. J., and S. P. He, 2012: Weakening relationship between East Asian winter monsoon and ENSO after mid-1970s. Chinese Science Bulletin, 57, 3535-3540.

Wang, H. J., and S. P. He, 2013: The increase of snowfall in Northeast China after the mid-1980s. Chinese Science Bulletin, 58, $1350-1354$

Wang, L., W. Chen, R. Q. Feng, and J. J. Liang, 2011: The seasonal march of the North Pacific Oscillation and its association with the interannual variations of China's climate in boreal winter and spring. Chinese J. Atmos. Sci., 35, 393-402. (in Chinese)

Yang, S., K.-M. Lau, and K.-M. Kim, 2002: Variations of the East Asian jet stream and Asian-Pacific-American winter climate anomalies. J. Climate, 15, 306-325.

Zhang, L., X. H. Zhu, K. Fraedrich, F. Sielmann, and X. F. Zhi, 2014: Interdecadal variability of winter precipitation in Southeast China. Climate Dyn., 43, 2239-2248.

Zhou, L. T., and R. G. Wu, 2010: Respective impacts of the East Asian winter monsoon and ENSO on winter rainfall in China. J. Geophys. Res., 115, D02107.

Zhou, L. T., C. Y. Tam, W. Zhou, and J. C. L. Chan, 2010: Influence of South China Sea SST and the ENSO on winter rainfall over South China. Adv. Atmos. Sci., 27(4), 832-844, doi: 10.1007/s00376-009-9102-7. 